Artículo

\title{
Activación de mecanismos de defensa en maíz pira mediante el uso del abono orgánico Microgeo ${ }^{\circledR}$
}

\author{
David Fernando Posso Suárez \\ Amanda do Prado Mattos ${ }^{\S}$ \\ Bruna Broti Rissato \\ Kátia Regina Freitas Schwan-Estrada \\ Departamento de Agronomía-Universidad Estadual de Maringá (UEM). Av. Colombo 5790, Zona 7, \\ Maringá, Brazil. PR. 87020-900. \\ ${ }^{\S}$ Autora para correspondencia: pradomattosa@gmail.com.
}

\section{Resumen}

La inducción de resistencia (IR) en plantas por productos naturales ha sido objeto de varios estudios, siendo estas activadas por moléculas elicitoras de origen biótica o abiótica. Los elicitores activan mecanismos de resistencia como las proteínas relacionadas a patogénesis (PRP's), que actúan en la protección de plantas impidiendo el desarrollo del patógeno. El presente estudio tiene como objetivo verificar la activación de PRP's (peroxidasa, catalasa, polifenoloxidasa e $\beta$ glucanasa) en plantas de maíz pira (Zea mays) tratadas con diferentes concentraciones $(0 \%, 0.5 \%$, $1 \%, 1.5 \%, 3 \%$ y $5 \%$ ) del biofertilizante comercial Microgeo ${ }^{\circledR}$. Analizando las enzimas PRP's se observó que el Microgeo ${ }^{\circledR}$ activó e incrementó la actividad de estas enzimas y que está inducción está más relacionada al tiempo de activación, pero no a la concentración utilizada.

Palabras clave: actividad enzimática, inductores, mecanismo de defensa, resistencia inducida.

Recibido: abril de 2020

Aceptado: julio de 2020 


\section{Introducción}

El cultivo de maíz es afectado por plagas y enfermedades, que son controladas mediante el uso indiscriminado de pesticidas, actividad que produce contaminación al ambiente y de las personas, además de la selección de razas resistentes de patógenos (Ghini y Kimati, 2002; Casela et al., 2006; Costa et al., 2012; Cota et al., 2013; Wordell-Filho et al., 2016). Una alternativa para el control de enfermedades en el cultivo de maíz es la inducción de resistencia, muy estudiada en el área de la fitopatología (Roncatto y Pascholati, 1998; Silva et al., 2008; Krzyzaniak et al., 2018; Lorenzetti et al., 2018).

Pascholati y Dalio (2018), reportan que la inducción de resistencia es la activación de los sistemas de defensa de la planta, cuando estas entran en contacto con los elicitores, por medio de la precepción y transducción de señales biológicas a nivel celular. Angelova et al. (2006), describen los elicitores como sustancias de origen biótica, como organismos viables y componentes de sus estructuras o de tipo abiótica como ácido salicílico, fosfitos, silicatos, entre otros.

También son considerados inductores de resistencia los biofertilizantes que actúan como potentes elicitores debido a la diversidad biótica y abiótica de su composición final que puede activar reacciones de defensa en la planta (Barros et al., 2010). Una característica de los inductores de resistencia es que no actúan del mismo modo que los agroquímicos convencionales, ya que presentan baja toxicidad al patógeno; sin embargo, tienen la capacidad de activar mecanismos de defensa latentes en las plantas (Colares y Bonaldo, 2014).

El uso de inductores para la activación de los mecanismos de resistencia en diferentes cultivos es una estrategia sustentable y con alto potencial en el control de enfermedades que puede ser adoptada en el cultivo de maíz. El objetivo de este estudio es verificar la inducción de proteínas relacionadas a la patogénesis, peroxidasa, catalasa, $\beta-1,3$ glucanase y polifenoloxidasa, en plantas de maíz pira (Zea mays) grupo genético Everta tratadas con diferentes concentraciones del abono orgánico Microgeo ${ }^{\circledR}$.

\section{Materiales y métodos}

La fase experimental fue realizada en el Laboratorio de Control Alternativo e Inducción de Resistencia de la Universidad Estadual de Maringá en Paraná, Brasil entre los meses de junio de 2017 a junio de 2018.

\section{Inductor de resistencia}

Para evaluar la inducción de proteínas relacionadas a la patogénesis en el maíz pira fue utilizado el biofertilizante Microgeo ${ }^{\circledR}$, que contiene en su composición, preparados biodinámicos, sustancias recalcitrantes, pentosas, minerales y salvados. Microgeo ${ }^{\circledR}$ es un producto que tiene componentes equilibrados que nutre, regula y mantiene la producción continua de fertilizantes biológicos; a través, del proceso continuo de compostaje de líquidos (CLC). 
En invernadero, en materas de $3 \mathrm{~L}$, en un sustrato compuesto de dos partes de suelo esterilizado, con una parte de arena esterilizada (2:1), fueron sembradas tres semillas de maíz pira variedad Pará, para un total de seis tratamientos y ocho repeticiones por tratamiento. A los 10 días después de la germinación las plantas de maíz pira, fueron tratadas con Microgeo ${ }^{\circledR}$. Fueron preparadas $100 \mathrm{ml}$ de las diferentes concentraciones $(0 \% ; 0.5 \% ; 1 \% ; 1.5 \% ; 3 \%$ y $5 \%)$ y con una única aplicación foliar fueron atomizadas ocho plantas por tratamiento.

Hasta punto de escurrimiento, las plantas tratadas permanecieron en invernadero por siete días. Como testigo se utilizaron plantas tratadas con agua destilada. Cada 24, 48, 72, 96 y 120 horas después de la aplicación del Microgeo ${ }^{\circledR}$ en las diferentes concentraciones, una hoja fue retirada, lavada en agua destilada y conservada en hielo y posteriormente pesada en balanza de precisión.

\section{Preparación del extracto enzimático}

El tejido colectado fue macerado en mortero con $\mathrm{N}_{2}$ líquido y homogenizado en tampón fosfato 50 mM y pH 7 + EDTA $0.1 \mathrm{mM}$. Posteriormente, el homogenizado fue transferido para dos tubos de microcentrífuga $(2 \mathrm{ml})$ por muestra, los cuales fueron centrifugados por $30 \mathrm{~min}$ a $12000 \mathrm{~g} / 4^{\circ} \mathrm{C}$, el sobrenadante obtenido, fue transferido a tubos de microcentrífuga $(2 \mathrm{ml})$ previamente rotulados y almacenados a $-20^{\circ} \mathrm{C}$ hasta el momento de la cuantificación.

\section{Análisis enzimático}

Los análisis enzimáticos fueron realizados por duplicado (dos tubos de microcentrífuga con $2 \mathrm{ml}$ de extracto enzimático). El extracto enzimático fue utilizado para evaluar el contenido de proteínas totales y de las enzimas peroxidasa, catalasa, polifenoloxidasa y $\beta-1.3$ glucanasa.

\section{Proteínas totales}

Para la determinación de las proteínas totales fue utilizado el método Bradford (1976), que mide la interacción entre la proteína de alto peso molecular y el colorante Coomassie Brilhant Blue -BG250. En $50 \mu \mathrm{l}$ de extracto enzimático, se adicionó $2.5 \mathrm{ml}$ de Bradford y se mezcló en vórtex. Después de $5 \mathrm{~min}$, fue realizada la lectura en cubeta de vidrio a $595 \mathrm{~nm}$ en espectrofotómetro.

Como blanco fue utilizado $50 \mu \mathrm{l}$ de agua destilada con $2.5 \mathrm{ml}$ de Bradford. La concentración de proteínas de cada muestra fue expresada $\mathrm{mg}$ proteína $\mathrm{ml}^{-1}$ de muestra, cuya absorbancia fue extrapolada en curva padrón de proteínas (ASB) $(\mathrm{Y}=0.845 \mathrm{x}-0.0227$ ). Donde: $\mathrm{Y}=\mathrm{es}$ la absorbancia a $595 \mathrm{~nm}$ y x= la concentración de proteína para cada $0.5 \mathrm{mg} \mathrm{mL}^{-1}$ de albumina de suero bovino.

\section{Actividad peroxidasa de guayacol}

La actividad de peroxidasa fue determinada a $30{ }^{\circ} \mathrm{C}$; a través del método espectrofotométrico directo, por la medida de la conservación del guayacol en tetraguayacol a $470 \mathrm{~nm}$ (Lusso y Pascholati, 1999). La mezcla de la solución consistió en $2.9 \mathrm{ml}$ de sustrato para enzima, $306 \mu 1$ de peróxido de hidrógeno, $250 \mu \mathrm{l}$ de guayacol al $2 \%$ y $87.5 \mathrm{ml}$ de tampón fosfato $0.01 \mathrm{M}(\mathrm{pH}$ 6) y $100 \mu \mathrm{l}$ de extracto enzimático. 
La reacción fue seguida en espectrofotómetro a $470 \mathrm{~nm}$, por un periodo de $2 \mathrm{~min}$. La actividad fue determinada por la variación ocurrida entre los valores extremos situados en el intervalo de incremento linear y expresada en $\mathrm{ABS} \mathrm{min}^{-1} \mathrm{mg}^{-1}$ proteína.

\section{Actividad catalasa}

La actividad de catalasa fue determinada por el complejo estable formado por el molibdato de amonio con peróxido de hidrógeno. Una alícuota de $100 \mu \mathrm{l}$ del extracto enzimático fue incubada en $0.5 \mathrm{ml}$ de mezcla de reacción conteniendo $60 \mathrm{mM}$ de peróxido de hidrógeno en tampón fosfato de potasio $60 \mathrm{mM}\left(\mathrm{pH} \mathrm{7.4)}\right.$ a $38^{\circ} \mathrm{C}$ durante $4 \mathrm{~min}$. Después de este periodo fue adicionado $0.5 \mathrm{ml}$ de $32.4 \mathrm{mM}$ de molibdato de amonio para paralizar la reacción y detener el consumo de peróxido de hidrógeno por la enzima en el extracto.

También se preparó un blanco para cada muestra, mediante la adición de molibdato de amonio a la mezcla de reacción, sin tener en cuenta el periodo de incubación. La lectura del complejo amarillo formado por el molibdato y peróxido de hidrógeno fue cuantificada a $405 \mathrm{~nm}$ en espectrofotómetro.

La diferencia entre la absorbancia del blanco y la muestra incubada determino la cantidad de peróxido de hidrogeno utilizado por la enzima. La concentración de $\mathrm{H}_{2} \mathrm{O}_{2}$, fue determinada utilizándose el coeficiente de extinción $€=0.0655 \mathrm{mM} \mathrm{cm}^{-1}$ y expresada en $\mu \mathrm{mol} \mathrm{min}{ }^{-1} \mathrm{mg}^{-1} \mathrm{de}$ proteína.

\section{Actividad polifenoloxidasa}

La actividad de polifenoloxidasa fue determinada por la metodología de Dungmal y Apenten (1999), para cuantificar la oxidación del catecol convertido en quinona, reacción medida por la enzima polifenoloxidasa. El sustrato para enzima consistió en una concentración de $20 \mathrm{mM}$ de catecol, disuelto en tampón fosfato de potasio $100 \mathrm{mM}$ (pH 6.8).

La reacción fue conducida a $30^{\circ} \mathrm{C}$, por la adición de $100 \mu \mathrm{l}$ de extracto enzimático en $900 \mu \mathrm{l}$ del sustrato, para posterior lectura en espectrofotómetro a $420 \mathrm{~nm}$, por el método directo, durante 2 min. La actividad fue determinada por la variación ocurrida entre los valores extremos situados en el intervalo de incremento linear y expresada en unit $\min ^{-1} \mathrm{mg}^{-1}$ proteína.

\section{Actividad $\beta-1,3$ glucanasa}

La actividad de $\beta$-1.3 glucanasa fue determinada por la cuantificación colorimétrica de azúcares reductores liberados con laminarina (Vogelsang y Braz, 1993). Para esto, se adicionó $150 \mu 1$ del extracto enzimático e $150 \mu \mathrm{l}$ de laminarina $\left(1.5 \mathrm{mg} \mathrm{ml}^{-1}\right)$ en tampón de extracción. Como control, se utilizó la misma reacción, solamente que la laminarina fue colocada antes de la incubación. 
La incubación para la reacción fue mantenida a $40{ }^{\circ} \mathrm{C}$ durante 60 min en baño maría. Pasado el periodo de incubación, se retiró una alícuota de $30 \mu \mathrm{l}$ de los tubos incubados en adición de $1.5 \mathrm{ml}$ de PAHBAH (0.5 g de 4-Hydroxybenhydrazide diluida en $20 \mathrm{ml}$ de $\mathrm{HCl} 0.5 \mathrm{M}$, e incrementado con $80 \mathrm{ml}$ de $\mathrm{NaOH} 0.5 \mathrm{M}$ ), cuya mezcla fue mantenida en baño maría a $100{ }^{\circ} \mathrm{C}$ por 5 min y posteriormente enfriadas en baño de hielo.

Los azucares reductores formados fueron cuantificados por el método de Lever (1972). La lectura de absorbancia se determinó a $410 \mathrm{~nm}$, en espectrofotómetro, descontándose los valores de absorbancia del blanco, siendo que la cuantidad de azucares se determinó utilizando la curva padrón de glucosa $(Y=1.1512 x+0.205)$. Donde: $Y=$ es la absorbancia a $410 \mathrm{~nm}$ y $\mathrm{x}=1 \mathrm{a}$ concentración de azucares reductores expresados en $\mathrm{mg}$ de glucosa $\mathrm{min}^{-1} \mathrm{mg}^{-1}$ de proteína.

\section{Análisis estadístico}

Cada unidad experimental estuvo representada por una matera con tres plantas de maíz pira. Los ensayos para análisis enzimático fueron conducidos por duplicado, con un delineamiento completamente al azar con ocho repeticiones. Fueron atendidos los presupuestos de la homogeneidad de las variancias y de la distribución de los dados, por el test de Levene y Shapiro Wilk respectivamente.

Los resultados obtenidos fueron sometidos a análisis de variancia $(p<0.05)$ por el test $\mathrm{F}$ y las medias de los tratamientos fueron analizadas por el test de Tukey y posterior análisis de regresión para evaluar las diferentes dosis de los tratamientos. Fue utilizado el programa de análisis estadístico y planeamiento de experimentos SISVAR 5.6 (Ferreira, 2014).

\section{Resultados y discusión}

\section{Catalasa}

Para la actividad específica de catalasa, la regresión fue significativa para el modelo cubico. En las primeras 24 h en la concentración de 3.7\% de Microgeo ${ }^{\circledR}$ se observó tres veces más de actividad de la enzima catalasa ( $44.3 \mu \mathrm{mol} \mathrm{min} \mathrm{mg}^{-1}$ proteína) comparado al tratamiento testigo, que fueron las plantas que se trataron solo con agua destilada (Figura 1A).

Para las 48 h la máxima actividad de la enzima fue observada en la concentración $1.87 \%$ con 51 $\mu \mathrm{mol} \mathrm{min} \mathrm{mg}^{-1} \mathrm{mg}^{-1}$ proteína, 2.5 veces más que el testigo (Figura 1B). Para las $72 \mathrm{~h}$ la máxima actividad de la enzima fue observada en la concentración $4.5 \%$ con $63 \mu \mathrm{mol} \mathrm{min}^{-1} \mathrm{mg}^{-1}$ proteína, valor 3.3 veces mayor que el tratamiento con agua (Figura 1C).

En la toma de muestras de hojas de las 96 h, con una concentración de $3.9 \%$ de Microgeo ${ }^{\circledR}$, se observó una actividad superior de catalasa de $56 \mu \mathrm{mol} \mathrm{min}{ }^{-1} \mathrm{mg}^{-1}$ proteína, resultado 2.6 veces superior al tratamiento con agua (Figura 1D). En el horario de $120 \mathrm{~h}$ se observó $64 \mu \mathrm{mol} \mathrm{min}{ }^{-1}$ $\mathrm{mg}^{-1}$ proteína en la concentración $1.3 \%$, valor 4 veces mayor que el tratamiento con agua (Figura $1 \mathrm{E})$. 

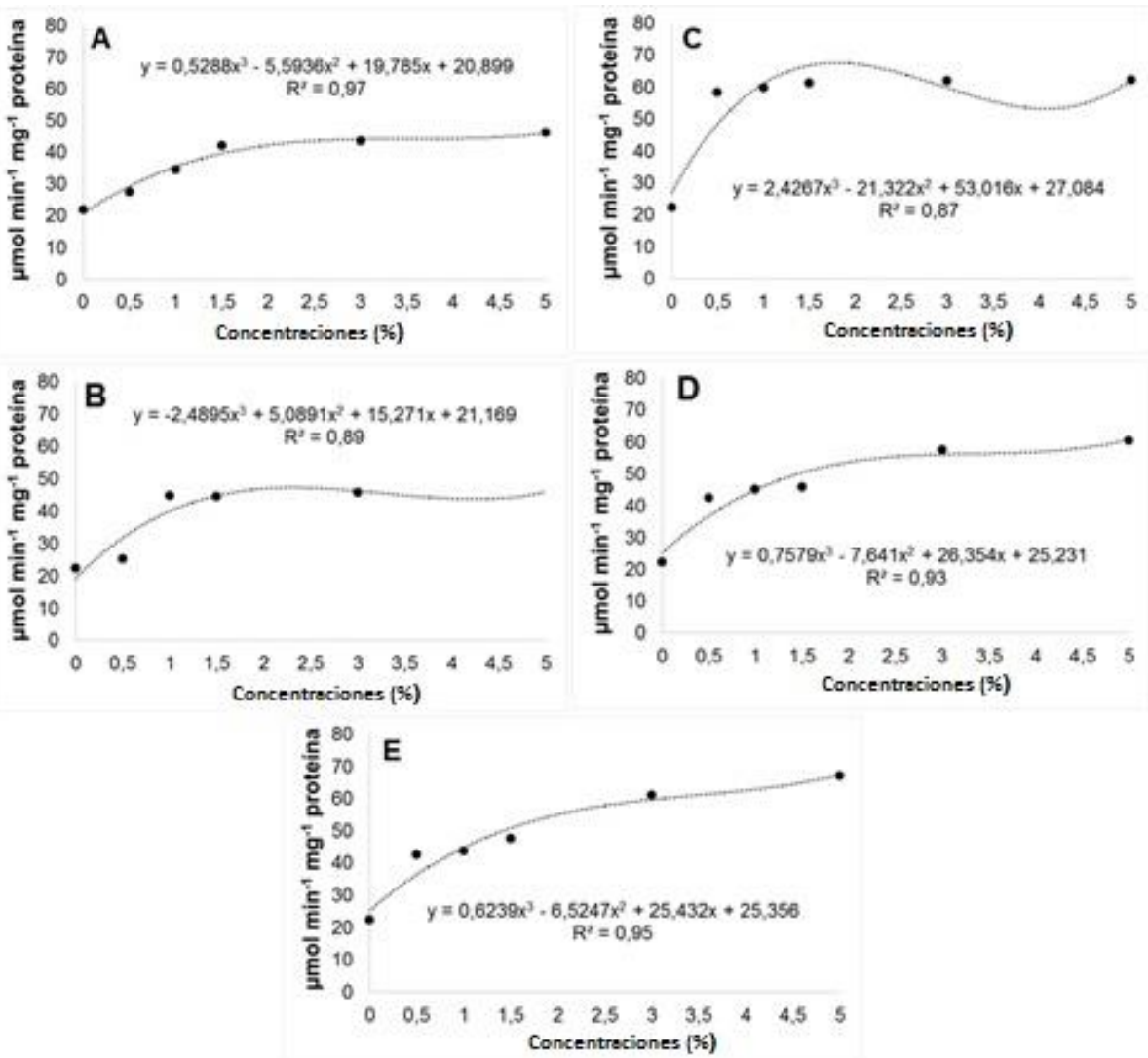

Figura 1. Actividad específica de catalasa en plantas de maíz pira en función del desdoblamiento de la interacción entre las diferentes concentraciones de Microgeo ${ }^{\circledR}$ dentro de los siguientes tiempos de toma de muestras de hojas: 24 h (A); 48 h (B); 72 h (C); 96 h (D); y 120 h (E); $\mathrm{CV}=3.45 \%$.

En todas las concentraciones de Microgeo $^{\circledR}$, excepto 0\%, indujeron la actividad específica de catalasa (Cuadro 1). A las 72 h después de la aplicación de las concentraciones $0.5,1,1.5 \%$ y $3 \%$ hubo el mayor incremento de la actividad de la enzima, al paso que en la concentración de 5\% ocurrió un aumento de la actividad 120 h después de la aplicación.

Cuadro 1. Actividad específica de catalasa ( $\mu \mathrm{mol} \mathrm{min}^{-1} \mathrm{mg}^{-1}$ proteína) en plantas de maíz pira en función del desdoblamiento de la interacción entre horarios de toma de muestras de hojas dentro de las concentraciones de Microgeo ${ }^{\circledR}$.

\begin{tabular}{ccccccc}
\hline \multirow{2}{*}{ Horarios (h) } & \multicolumn{7}{c}{ Concentraciones $(\%)$} \\
\cline { 2 - 7 } & 0 & 0.5 & 1 & 1.5 & 3 & 5 \\
\hline 24 & $22.03 \mathrm{a}$ & $27.59 \mathrm{c}$ & $34.51 \mathrm{c}$ & $42.23 \mathrm{~d}$ & $43.48 \mathrm{c}$ & $46.19 \mathrm{c}$ \\
48 & $22.26 \mathrm{a}$ & $25.26 \mathrm{c}$ & $44.67 \mathrm{c}$ & $44.65 \mathrm{~cd}$ & $45.19 \mathrm{c}$ & $45.94 \mathrm{c}$ \\
72 & $22.4 \mathrm{a}$ & $58.45 \mathrm{a}$ & $59.75 \mathrm{a}$ & $61.24 \mathrm{a}$ & $61.9 \mathrm{a}$ & $62.13 \mathrm{~b}$ \\
96 & $22.42 \mathrm{a}$ & $42.44 \mathrm{~b}$ & $44.97 \mathrm{a}$ & $45.69 \mathrm{bc}$ & $57.51 \mathrm{~b}$ & $60.5 \mathrm{~b}$ \\
120 & $22.52 \mathrm{a}$ & $42.45 \mathrm{~b}$ & $43.82 \mathrm{~b}$ & $47.69 \mathrm{c}$ & $61.05 \mathrm{a}$ & $67.2 \mathrm{a}$ \\
CV \% & & \multicolumn{7}{c}{3.45} & \\
\hline
\end{tabular}

Medias seguidas por la misma letra en las columnas no difieren significativamente entre sí por la prueba de Tukey $(p<$ 0.05 ). 


\section{Peroxidasa de guayacol}

En la actividad específica de peroxidasa, se observó por el desdoblamiento de las concentraciones dentro de los horarios de toma de muestras de hojas, que el modelo de regresión fue significativo con ajuste cúbico (Figura 2). En la concentración de 2.4\% de Microgeo ${ }^{\circledR}$, se observó 1.6 veces más actividad de la enzima peroxidasa (23.24 ABS $\mathrm{min}^{-1} \mathrm{mg}^{-1}$ proteína), cuando comparado al tratamiento con agua, a las $24 \mathrm{~h}$ (Figura 2A).

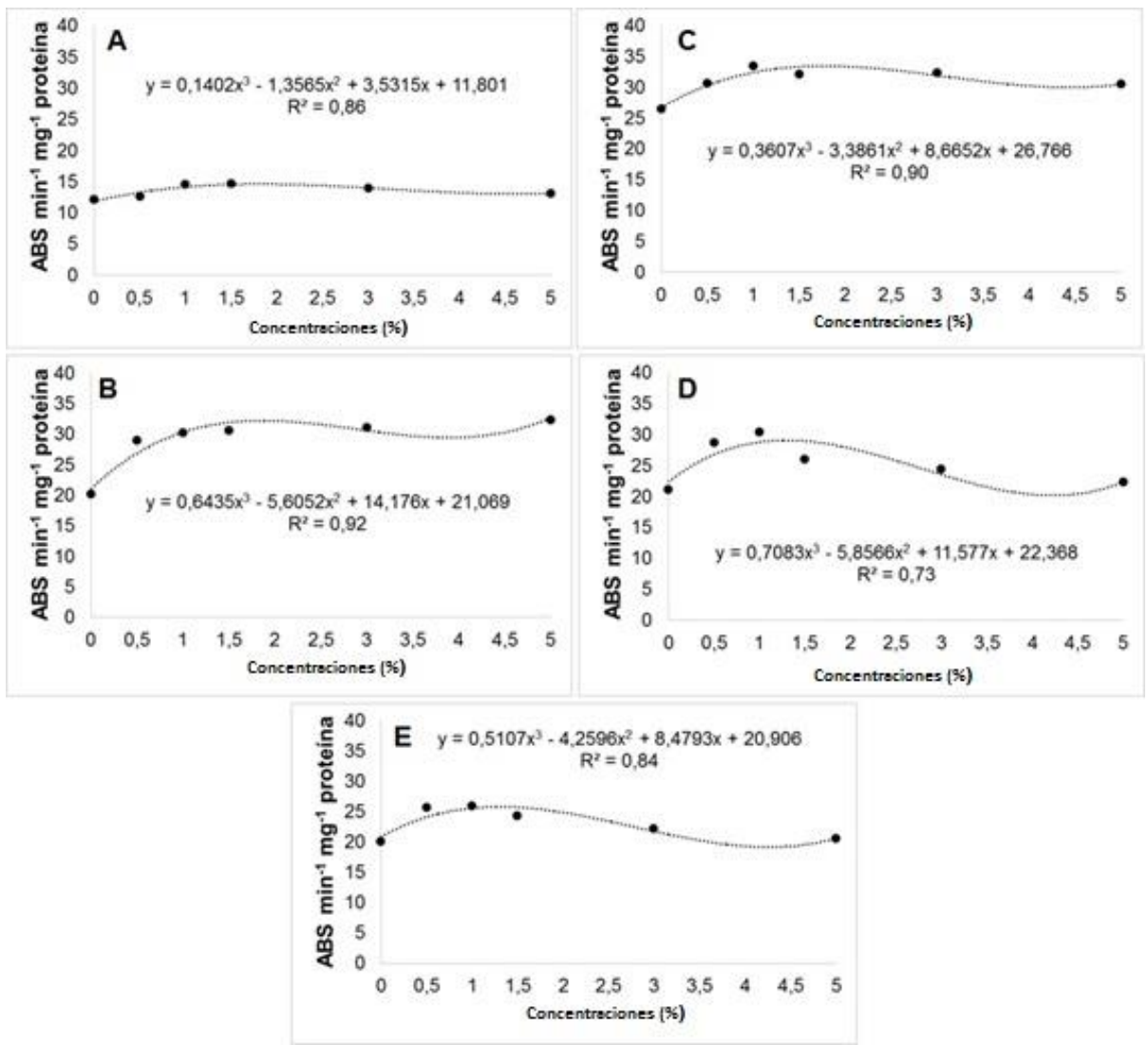

Figura 2. Actividad específica de peroxidasa en plantas de maíz pira en función del desdoblamiento de la interacción entre las diferentes concentraciones de Microgeo ${ }^{\circledR}$ dentro de los siguientes tiempos de toma de muestras de hojas: 24 h (A); 48 h (B); 72 h (C); 96h (D); y 120 h (E); $\mathrm{CV}=7 \%$.

En el horario de las $48 \mathrm{~h}$, la máxima actividad de la peroxidasa fue observada en la concentración $1.7 \%$ con $22.97 \mathrm{ABS} \mathrm{min}^{-1} \mathrm{mg}^{-1}$ proteína, valor 1.1 veces mayor que el tratamiento con agua (Figura 2B). En el horario $72 \mathrm{~h}$, la máxima actividad enzimática de peroxidasa fue observada en la concentración de $1.7 \%$ con $47.68 \mathrm{ABS} \mathrm{min}^{-1} \mathrm{mg}^{-1}$ proteína, valor 1.6 veces mayor que el tratamiento con agua (Figura $2 \mathrm{C}$ ).

En la concentración de 3\% se observó una actividad enzimática de 34 ABS min ${ }^{-1} \mathrm{mg}^{-1}$ proteína, valor 1.6 veces mayor que el tratamiento con agua (Figura 3D). En el horario de las $120 \mathrm{~h}$ se observó $46.84 \mathrm{ABS} \mathrm{min}^{-1} \mathrm{mg}^{-1}$ proteína en la concentración de $2.4 \%$, valor superior 2.8 veces al tratamiento control. 
Todas las concentraciones de Microgeo ${ }^{\circledR}$, excepto $0 \%$, indujo actividad específica de peroxidasa (Cuadro 2). 72 h después de la aplicación en las concentraciones $0.5 ; 1 ; 1.5$ y 3\%, hubo el mayor incremento de la actividad de la enzima y en la concentración 5\% hubo un aumento de la actividad 120 h después de la aplicación.

Cuadro 2. Actividad específica de peroxidasa (ABS min-1 $\mathrm{mg}^{-1}$ proteína) en plantas de maíz pira en función del desdoblamiento de la interacción entre horarios de toma de muestras de hojas dentro de las concentraciones de Microgeo ${ }^{\circledR}$.

\begin{tabular}{ccccccc}
\hline \multirow{2}{*}{ Horarios (horas) } & \multicolumn{7}{c}{ Concentraciones (\%) } \\
\cline { 2 - 7 } & 0 & 0.5 & 1 & 1.5 & 3 & 5 \\
\hline 24 & $14.4 \mathrm{~d}$ & $16.02 \mathrm{c}$ & $21.6 \mathrm{~d}$ & $22.65 \mathrm{c}$ & $22.75 \mathrm{c}$ & $23.02 \mathrm{c}$ \\
48 & $19.92 \mathrm{bc}$ & $22.35 \mathrm{~b}$ & $22.4 \mathrm{~cd}$ & $22.7 \mathrm{bc}$ & $22.78 \mathrm{c}$ & $23.43 \mathrm{c}$ \\
72 & $29.42 \mathrm{a}$ & $44.58 \mathrm{a}$ & $44.55 \mathrm{a}$ & $44.98 \mathrm{a}$ & $44.96 \mathrm{a}$ & $42.71 \mathrm{~b}$ \\
96 & $21.95 \mathrm{~b}$ & $23.83 \mathrm{~b}$ & $25.94 \mathrm{c}$ & $33.14 \mathrm{~b}$ & $33.2 \mathrm{~b}$ & $39.41 \mathrm{~b}$ \\
120 & $16.25 \mathrm{~cd}$ & $23.6 \mathrm{~b}$ & $31.98 \mathrm{~b}$ & $45.06 \mathrm{a}$ & $49.21 \mathrm{a}$ & $82.69 \mathrm{a}$ \\
CV $(\%)$ & & & & & & \\
\hline
\end{tabular}

Medias seguidas por la misma letra en las columnas no difieren significativamente entre sí por el test de Tukey ( $p<$ 0.05). Actividad enzimática, inductores, mecanismo de defensa y resistencia inducida.

\section{Polifenoloxidasa}

El desdoblamiento de las concentraciones dentro de los horarios de toma de muestras de hojas fue significativo para modelo de regresión cúbico al analizar polifenoloxidasa (Figura 3). En la concentración $1.8 \%$ de Microgeo $^{\circledR}$, se observó 1.3 veces más actividad de la enzima polifenoloxidasa (3.4 unit $\mathrm{min}^{-1} \mathrm{mg}^{-1}$ proteína).

Cuando comparado al tratamiento con agua 24 h (Figura 3A). En el horario de las 48 h, la máxima actividad de polifenoloxidasa fue observado en la concentración de $4.2 \%$ con 3.6 unit min $\mathrm{mg}^{-1}$ proteína, valor 1.1 veces mayor que el tratamiento con agua (Figura 3B).

En el horario de 72 h la máxima actividad enzimática fue observada en la concentración de $1.7 \%$ con 9.3 unit $\mathrm{min}^{-1} \mathrm{mg}^{-1}$ proteína, valor 2.5 veces superior al tratamiento con agua (Figura 3C). En la concentración 3\% se observó una actividad enzimática de 4.2 unit min ${ }^{-1} \mathrm{mg}^{-1}$ proteína, valor 1.2 veces superior que al tratamiento con agua (Figura 3D). En el horario de $120 \mathrm{~h}$ se observó 4.53 unit $\mathrm{min}^{-1} \mathrm{mg}^{-1}$ proteína en la concentración 5\%, valor 1.2 veces mayor que el tratamiento control.

En todas las concentraciones de Microgeo $^{\circledR}$, excepto $0 \%$, indujeron actividad específica de polifenoloxidasa (Cuadro 3). En las 72 h después a la aplicación de las concentraciones de $0.5 \%$, $1 \%, 1.5 \%$ y $3 \%$ hubo el mayor incremento de la actividad de la enzima, al paso que en la concentración 5\% hubo un aumento de la actividad 120 h después de la aplicación. 

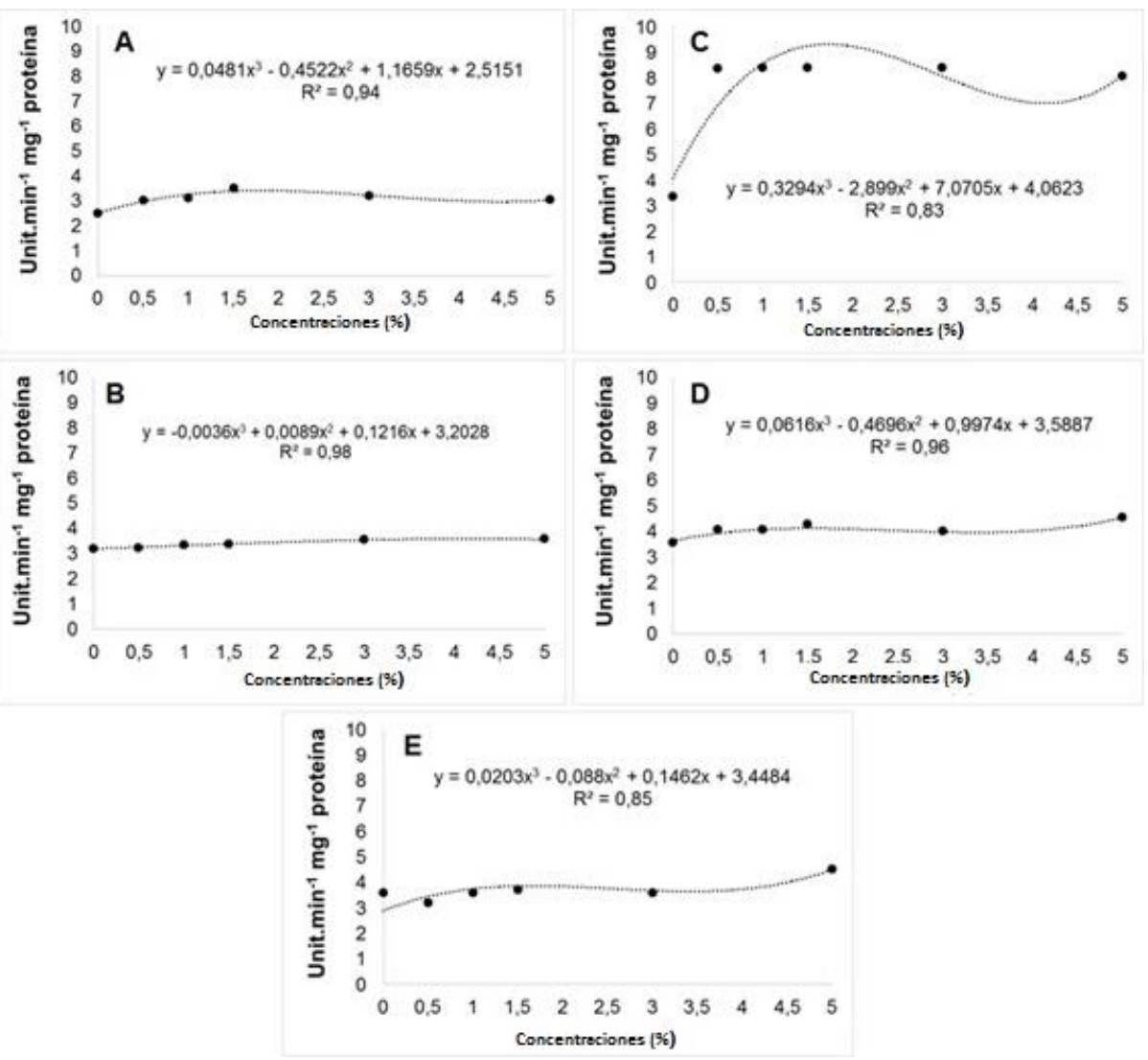

Figura 3. Actividad específica de polifenoloxidasa en plantas de maíz pira en función del desdoblamiento de la interacción entre las diferentes concentraciones de Microgeo $^{\circledR}$ dentro de los siguientes tiempos de toma de muestras de hojas: 24 h (A); 48 h (B); 72 h (C); 96 h (D); y 120 h (E); CV= 7\%.

Cuadro 3. Actividad específica de polifenoloxidasa (unit $\mathrm{min}^{-1} \mathrm{mg}^{-1}$ proteína) en plantas de maíz pira en función del desdoblamiento de la interacción entre horarios de toma de muestras de hojas dentro de las concentraciones de Microgeo $^{\circledR}$.

\begin{tabular}{ccccccc}
\hline \multirow{2}{*}{ Horarios (horas) } & \multicolumn{7}{c}{ Concentraciones (\%) } \\
\cline { 2 - 7 } & 0 & 0.5 & 1 & 1.5 & 3 & 5 \\
\hline 24 & $2.52 \mathrm{~b}$ & $3.03 \mathrm{c}$ & $31.4 \mathrm{c}$ & $3.52 \mathrm{~b}$ & $3.22 \mathrm{~b}$ & $3.05 \mathrm{c}$ \\
48 & $3.21 \mathrm{ab}$ & $3.24 \mathrm{bc}$ & $3.36 \mathrm{bc}$ & $3.38 \mathrm{~b}$ & $3.55 \mathrm{~b}$ & $3.58 \mathrm{c}$ \\
72 & $3.37 \mathrm{ab}$ & $8.36 \mathrm{a}$ & $8.39 \mathrm{a}$ & $8.4 \mathrm{a}$ & $8.4 \mathrm{a}$ & $8.07 \mathrm{a}$ \\
96 & $3.56 \mathrm{a}$ & $4.07 \mathrm{~b}$ & $4.08 \mathrm{~b}$ & $4.27 \mathrm{~b}$ & $4.02 \mathrm{~b}$ & $4.54 \mathrm{~b}$ \\
120 & $3.05 \mathrm{a}$ & $3.2 \mathrm{bc}$ & $3.58 \mathrm{bc}$ & $4.22 \mathrm{~b}$ & $3.58 \mathrm{~b}$ & $4.53 \mathrm{~b}$ \\
$\mathrm{CV}(\%)$ & & \multicolumn{7}{c}{10.83} & & \\
\hline
\end{tabular}

Medias seguidas por la misma letra en las columnas no difieren significativamente entre sí por el test de Tukey $(p<$ $0.05)$. 


\section{B 1.3-glucanase}

El desdoblamiento de las concentraciones dentro de los horarios de toma de muestras de hojas fue significativo para el modelo de regresión cubico al analizar $\beta$ 1.3-glucanase (Figura 4). En la concentración de $1.8 \%$ de Microgeo ${ }^{\circledR}$, se observó 1.3 veces más actividad de la enzima glucanasa (3.4 mg glucosa $\mathrm{min}^{-1} \mathrm{mg}^{-1}$ proteína), cuando comparado al tratamiento con agua a las $24 \mathrm{~h}$ (Figura 4A).

En el horario de las 48 h, la máxima actividad de glucanasa fue observada en la concentración de $4.2 \%$ con $3.6 \mathrm{mg}$ glucosa $\mathrm{min}^{-1} \mathrm{mg}^{-1}$ proteína, resultado 1.1 veces mayor que el tratamiento con agua (Figura 4B). En el horario de las 72 h, la máxima actividad de esta enzima fue observada en la concentración de $1.7 \%$ con $9.3 \mathrm{mg}$ glucosa $\mathrm{min}^{-1} \mathrm{mg}^{-1}$ proteína, valor 2.5 veces superior al tratamiento con agua (Figura 4C).
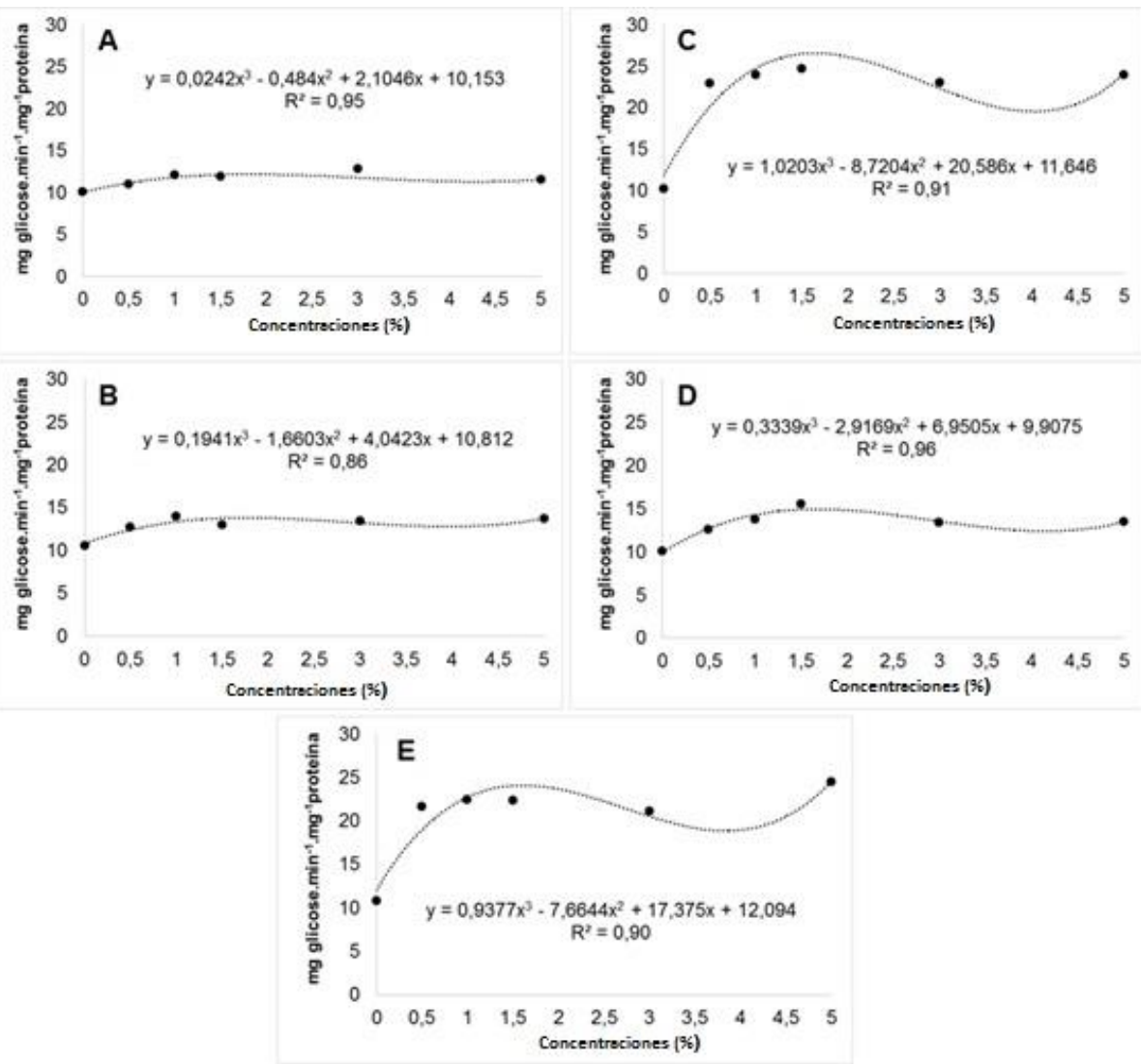

Figura 4. Actividad específica de $\beta 1.3$ glucanasa en plantas de maíz pira en función del desdoblamiento de la interacción entre las diferentes concentraciones de Microgeo ${ }^{\circledR}$ dentro de los siguientes tiempos de toma de muestras de hojas: 24 h (A); 48 h (B); 72 h (C); 96 h (D); y 120 h (E); CV=7\%.

En la concentración 3\% se observó una actividad enzimática de $4.2 \mathrm{mg}$ glucosa $\mathrm{min}^{-1} \mathrm{mg}^{-1}$ proteína, valor 1.2 veces superior que al tratamiento con agua (Figura 4D). En el horario 120 h, se observó $4.53 \mathrm{mg}$ glucosa $\mathrm{min}^{-1} \mathrm{mg}^{-1}$ proteína en la concentración de 5\%, valor 1.2 veces mayor al tratamiento control (Figura 4E). 
Todas las concentraciones de Microgeo ${ }^{\circledR}$, excepto $0 \%$ indujeron actividad específica de glucanasa, con un pico de actividad $72 \mathrm{~h}$ después de la aplicación de las concentraciones $0.5 \%, 1 \%, 1.5 \%, 3 \%$ y $5 \%$ y otro 120 h después de la aplicación (Cuadro 4).

Cuadro 4. Actividad específica de $\beta$ 1.3-glucanase (mg glucosa $\mathrm{min}^{-1} \mathrm{mg}^{-1}$ proteína) en plantas de maíz pira en función del desdoblamiento de la interacción ente horarios de toma de muestras de hojas dentro de las concentraciones de Microgeo ${ }^{\circledR}$.

\begin{tabular}{ccccccc}
\hline \multirow{2}{*}{ Horarios (h) } & \multicolumn{7}{c}{ Concentraciones $(\%)$} \\
\cline { 2 - 7 } & 0 & 0.5 & 1 & 1.5 & 3 & 5 \\
\hline 24 & $10.11 \mathrm{a}$ & $11.05 \mathrm{~b}$ & $12.14 \mathrm{~b}$ & $11.98 \mathrm{c}$ & $11.83 \mathrm{~b}$ & $11.59 \mathrm{~b}$ \\
48 & $10.58 \mathrm{a}$ & $12.7 \mathrm{~b}$ & $13.97 \mathrm{~b}$ & $13.02 \mathrm{bc}$ & $13.43 \mathrm{~b}$ & $13.75 \mathrm{~b}$ \\
72 & $10.22 \mathrm{a}$ & $23.94 \mathrm{a}$ & $23.97 \mathrm{a}$ & $24.74 \mathrm{a}$ & $23.11 \mathrm{a}$ & $24.02 \mathrm{a}$ \\
96 & $10.06 \mathrm{a}$ & $12.57 \mathrm{~b}$ & $13.77 \mathrm{~b}$ & $15.5 \mathrm{~b}$ & $13.38 \mathrm{~b}$ & $13.5 \mathrm{~b}$ \\
120 & $10.8 \mathrm{a}$ & $21.66 \mathrm{a}$ & $22.49 \mathrm{a}$ & $22.42 \mathrm{a}$ & $21.17 \mathrm{a}$ & $24.48 \mathrm{a}$ \\
$\mathrm{CV}(\%)$ & & & 7 & & \\
\hline
\end{tabular}

Medias seguidas por la misma letra en las columnas no difieren significativamente entre sí por la prueba de Tukey ( $p<$ $0.05)$.

En general se observó que el aumento de la actividad de las enzimas catalasa, peroxidasa, polifenoloxidasa y $\beta$-1.3-glucanase, inició $24 \mathrm{~h}$ después a la aplicación de Microgeo ${ }^{\circledR}$, principalmente en las dosis de 1 y $1.5 \%$, de manera que la actividad enzimática más intensa fue registrada entre 72 y 96 h después de la aplicación de los tratamientos. La actividad de la catalasa fue observada $24 \mathrm{~h}$ después de tratar las plantas con las diferentes concentraciones de Microgeo ${ }^{\circledR}$, siendo las mayores actividades registradas a las 72 y $96 \mathrm{~h}$ en las concentraciones $1 \%$ y $1.5 \%$.

Resultados similares fueron encontrados por Sytykiewicz (2015) confirmando alteraciones significativas en las respuestas de transcripción de genes catalasa en diferentes híbridos de maíz, cuando fueron expuestos a herbívora por áfidos o como Lanubile et al. (2012), que encontraron que las espigas de maíz inoculadas con Fusarium verticilloides, se protegen contra el estrés oxidativo y contra el ataque del patógeno, induciendo mayor actividad enzimática de catalasa.

En la actividad de la enzima peroxidasa, se observó que su actividad inició 24 h después de las plantas ser tratadas, siendo las mayores actividades registradas entre las 48 y 72 h; sin embargo, también se observó actividad de peroxidasa en las plantas no tratadas. Resultados similares obtuvieron Cadena-Gómez y Nicholson (1987), que observaron actividad de peroxidase $12 \mathrm{~h}$ después a la inoculación de plantas de maíz con Helminthosporium maydis o Colletotrichum graminicola, de manera que los mayores registros de actividad de esta enzima fueron observados $36 \mathrm{~h}$.

Después de la inoculación; como también reportaron actividad de peroxidasa en las plantas no inoculadas. La actividad de polifenoloxidasa, inició $24 \mathrm{~h}$ después de la aplicación de los tratamientos, siendo la mayor actividad de la enzima alcanzada a las 72 h en la concentración de $1.5 \%$, resultados similares fueron encontrados por Cadena-Gómez y Nicholson (1987). 
Quienes encontraron fenoles en plantas de maíz 12 h después de estar ser inoculadas con Helminthosporium maydis o Colletotrichum graminicola. En cuanto a la enzima $\beta-1.3$ glucanasa, su actividad inició $24 \mathrm{~h}$ después de la aplicación de los tratamientos y el pico mayor de actividad fue registrado a las $120 \mathrm{~h}$, con dosis de 1 y $1.5 \%$ de Microgeo $^{\circledR}$.

\section{Conclusiones}

De acuerdo con los resultados obtenidos en esta investigación, se concluye que el biofertilizante Microgeo ${ }^{\circledR}$, presenta resultados positivos para la inducción de actividad enzimática en plantas de maíz pira, ya que induce la activación de enzimas relacionadas a la patogénesis (catalasa, peroxidasa, polifenoloxidasa y $\beta-1.3$ glucanasa) de manera que la mayor actividad ocurre $72 \mathrm{~h}$ después de la aplicación de Microgeo ${ }^{\circledR}$ y en la concentración de $1 \%$.

\section{Literatura citada}

Angelova, Z.; Georgiev, S. and Roos, W. 2006. Elicitation of plants. Biotechnol. Biotechnological Equipment. 20(2):72-83. https://doi.org/10.1080/13102818.2006.10817345.

Barros, F. C.; Sagata, E.; Ferreira, L. C. and. Juliatti, F. C. 2010 Indução de resistência em plantas à fitopatógenos. Induction of resistance in plants against phytopathogens. Bios. J. 26(2):231-239.

Bradford, M. M. 1976. A rapid and sensitive method for the quantitation of microgram quantities of protein utilizing the principle of protein-dye binding. Analytical Biochem. 7(2):248-254. https://doi.org/10.1016/0003-2697 (76)90527-3.

Cadena-Gómez, G. and Nicholson, R. L. 1987. Papilla formation and associated peroxidase activity: A non-specific response to attempted fungal penetration of maize. Physiol. Mol. Plant Pathol. 31(1):51-67. https://doi.org/10.1016/0885-5765(87)90006-3.

Casela, C. R.; Ferreira, A. S. and Pinto, N. F. J. A. 2006. Doenças na Cultura do Milho. Embrapa Milho e Sorgo. Circular Técnica. 83(1):1-14.

Colares, M. R. N. and Bonaldo, S. M. 2014. Uso de biofertilizantes na indução de resistência em plantas a patógenos. In: Schwan-Estrada, K. R. F.; Silva, C. M.; Maia, A. J.; Faria, C. M. D. R. and Colella, J. C. T. (Org.). Indução de resistência em plantas a patógenos. VII Ed.maringá: suprema gráfica e editora LTDA. 55-72 pp.

Costa, D. F.; Vieira, B. F.; Lopes, E. A. and. Moreira, L. C. B. 2012. Aplicação de fungicidas no controle de doenças foliares na cultura do milho. Ver. Brasileira de Milho e Sorgo, 11(1):98-105.

Cota, L.V.; Costa, R.V.; Sabato, E. O. and Silva, D. D. 2013. Histórico e perspectivas das doenças na cultura do milho. Embrapa Milho e Sorgo. Circular Técnica. 19(1):1-7.

Duangmal, K. and Apenten, R. K. O. 1999. A comparative study of polyphenoloxidases from taro (Colocasia esculenta) and potato (Solanum tuberosum var. romano). Food Chem. 64(3):351-359. https://doi.org/10.1016/S0308-8146 (98)00127-7.

Ferreira, D. F. 2014. Sisvar: a guide for its bootstrap procedures in multiple comparisons. Ciência e Agrotecnologia. 38(2):109-112. http://dx.doi.org/10.1590/S1413-70542014000200001.

Ghini, R. and Kimati, H. 2002 Resistência de fungos a fungicidas. Jaguariúna, SP: Embrapa Meio Ambiente. 78 p. 
Krzyzaniak, Y.; Trouvelot, S.; Negrel, J.; Cluzet, S.; Valls J.; Richard, T.; Bougaud, A.; Jacquens, L.; Klinguer, A.; Chiltz, A.; Adrian, M. and Héloir, M. 2018. A plant extract acts both as a resistance inducer and an oomycide against grapevine downy mildew. Frontiers in Plant Sci. 9(1):10-85.

Lanubile, A.; Bernardi, J.; Marocco, A.; Logrieco, A. and Paciolla, C. 2012. Differential activation of defense genes and enzymes in maize genotypes with contrasting levels of resistance to Fusarium verticillioides. Environ. Exp. Bot. 78(1):39-46. https://doi.org/10.1016/ j.envexpbot.2011.12.006.

Lever, M. 1972. A new reaction for colorimetric determination of carbohydrates. Analytical Biochem. 47(1):273-279. https://doi.org/10.1016/0003-2697(72)90301-6.

Lorenzetti, E.; Stangarlin, J. R.; Kuhn, O. J. and Portz, R. L. 2018. Indução de resistência à Macrophomina phaseolina em soja tratada com extrato de alecrim. Summa Phytopathol. Botucatu. 44(1):45-50.

Lusso, M. F. G. and Pascholati, S. F. 1999. Activity and isoenzymatic pattern of soluble peroxidases in maize tissues after mechanical injury or fungal inoculation. Summa Phytopathol. 25(3):244-249.

Pascholati, S. F. and Dalio, R. J. D. 2018 Fisiología do Parasitismo: Como as plantas se defendem dos patógenos. In: manual de fitopatologia: principios y conceptos. Ouro Fino-MG. Agron. Ceres. $573 \mathrm{p}$.

Roncatto, M. C. and Pascholati, S. F. (1998) Alterações na atividade e no perfil eletroforético da peroxidase em folhas de milho (Zea mays) e sorgo (Sorghum bicolor) tratadas com levedura (Saccharomyces cerevisiae). Scientia Agricola Piracicaba. 55(3):395-402.

Silva, R. F.; Pascholati, S. F. and Bedendo, I. P. 2008. Indução de resistência em plantas de berinjela por Lentinula edodes e Agaricus blazei contra Ralstonia solanacearum: aspectos bioquímicos e biomassa vegetal. Summa Phytopathol. 34(2):137-144.

Sytykiewicz, H. 2015 Transcriptional responses of catalase genes in maize seedlings exposed to cereal aphids' herbivory. Biochem. Systematics Ecol. 60(1):131-142. https://doi.org/10.1016/j.bse.2015.04.015.

Vogelsang, R. and Barz, W. 1993. Purification, characterization and differential hormonal regulation of a $\beta$-1, 3-glucanase and 2 chitinases from chickpea (Cicer arietinum L.). Planta. 189(1):60-69. https://doi.org/10.1007/BF00201344.

Wordell-Filho, J. A.; Ribeiro, L. do P.; Chiaradia, L. A.; Madalóz, J. C. and. Neri, C. N. 2016. pragas e doenças do milho: diagnose, danos e estratégias de manejo. Florianópolis: Epagri. Epagri. Boletim técnico 170. 82 p. 